\title{
Reação de cultivares de batata a Streptomyces scabies, agente causal da sarna comum profunda
}

\author{
Ivan Herman Fischer ${ }^{1}$, Ana Paula Matoso Teixeira ${ }^{2}$, Leonardo Toffano², Ely Oliveira Garcia ${ }^{2}$
}

\begin{abstract}
${ }^{1}$ Agência Paulista de Tecnologia dos Agronegócios, Av. Rodrigues Alves 40-40, CEP 17030-000, Bauru,SP, Fax (14) 3203-3257; ${ }^{2}$ Departamento de Entomologia, Fitopatologia e Zoologia Agrícola, Escola Superior de Agricultura "Luiz de Queiroz", Universidade de São Paulo, CP 09, CEP 13418-900, Piracicaba, SP.
\end{abstract}

Autor para correspondência: Ivan Herman Fischer (ihfische@ apta.sp.gov.br)

Data de chegada: 04/06/2007. Aceito para publicação em: 02/02/2009

\section{RESUMO}

Fischer, I.H.; Teixeira, A.P.M.; Toffano, L.; Garcia, E.O. Reação de cultivares de batata a Streptomyces scabies, agente causal da sarna comum profunda. Summa Phytopathologica, v.35, n.3, p.219-222, 2009

Este trabalho visou caracterizar quanto a critérios morfológicos e fisiológicos isolados de Streptomyces causadores de sarna comum profunda em batata; avaliar o comportamento de cultivares em relação à doença e a variação na agressividade entre os isolados da bactéria. Os isolados de Streptomyces apresentaram coloração cinza em meio extrato de levedura e malte e cadeias de esporos espiraladas, produzidas sobre um micélio aéreo. Ocorreu produção de melanina em meio de tirosina-ágar e a utilização de oito fontes de carbono recomendadas, propriedades estas que correspondem às descritas para S. scabies. Batatas-semente sadias de seis cultivares foram plantadas em substrato infestado com seis isolados de S. scabies separadamente e as plantas cultivadas em vasos e ambiente aberto.
A severidade da doença foi estimada com auxílio de uma escala diagramática e avaliou-se o rendimento de tubérculos (g/planta). As cvs. Mondial e Jaete Bintje foram as mais resistentes à sarna comum com severidade média nos dois experimentos de $10,5 \%$ e $14,0 \%$, respectivamente, seguidas por Asterix $(17,4 \%)$, Ágata $(21,8 \%)$, Monalisa (23,0\%) e Cupido (23,3\%). A agressividade dos isolados variou quantitativamente, com severidade maior para o isolado M4 (34,7\%) e menor para o isolado M1 (6,2\%). Redução da produção de tubérculos foi verificada na cv. Jaete Bintje, no primeiro experimento, e quando as cultivares foram infectadas pelos isolados A1, M2 e M3, no primeiro experimento, e pelo isolado M4, no segundo experimento.

Palavras-chave adicionais: Solanum tuberosum, resistência varietal, patogenicidade.

\section{ABSTRACT}

Fischer, I.H.; Teixeira, A.P.M.; Toffano, L.; Garcia, E.O. Reaction of potato cultivars to Streptomyces scabies, causal agent of deep common scab. Summa Phytopathologica, v.35, n.3, p.219-222, 2009

This work aimed to characterize the isolates of Streptomyces, responsible for deep common scab symptoms in potato, according to morphological and physiological criteria; to evaluate the resistance of potato cultivars to the disease and the aggressiveness of bacterium isolates. The Streptomyces isolates presented gray coloration on yeast extract and malt medium and spiral spore chains, produced on aerial hyphae. Production of melanina occurred in tirosine-agar medium and the utilization of eight recommended carbon sources. These properties correspond to the S. scabies species. Healthy potato seeds of six cultivars were planted in substratum infested with six isolates of S. scabies separately, and the plants cultivated in plastic bags and under open sky. The scab severity was evaluated with a diagrammatic scale and evaluated the tuber production (g/plant). Cvs. Mondial and Jaete Bintje were the most resistant to the common scab with average severity of $10.5 \%$ and $14.0 \%$, respectively, followed by cv. Asterix $(17.4 \%)$, Agata $(21.8 \%)$, Monalisa $(23.0 \%)$ and Cupido $(23.3 \%)$. The aggressiveness of the isolates varied quantitatively, with higher severity for the isolate M4 (34.7\%) and minor for the isolate M1 (6.2\%). Reduction of tuber production was verified in cv. Jaete Bintje in the first experiment, and when the cultivars were infected by isolates A1, M2 and M3 in the first experiment and by isolate M4 in the second experiment.

Keywords: Solanum tuberosum, varietal resistance, pathogenicity.

A sarna comum é encontrada em todas as áreas produtoras de batata (Solanum tuberosum L.) do mundo e causa a depreciação do produto, devido a formação de lesões corticosas nos tubérculos, tanto superficiais quanto profundas. A doença é causada por bactérias filamentosas Gram-positivas do gênero Streptomyces (14).

A espécie Streptomyces scabies (Thaxter) Waksman \& Henrici é a mais encontrada causando a sarna comum $(2,10)$, mas outras como $S$. acidiscabies Lambert \& Loria, S. turgidiscabies Takeuchi e $S$. caviscabies Goyer, Faucher \& Beaulieu também podem incitar sintomas semelhantes da doença. As espécies de Streptomyces causadoras de sarna comum diferenciam-se entre si por critérios morfológicos, fisiológicos e genéticos $(2,18,24)$. A ocorrência dos sintomas de sarna profunda depende da resistência da cultivar de batata, da agressividade da bactéria e dos níveis de pH e umidade do solo (25).

Para prevenir o aparecimento da sarna comum, várias medidas devem ser adotadas em conjunto. O plantio de batata-semente 
certificada isenta da bactéria é uma das mais importantes, pois afeta diretamente a população inicial do patógeno. A monocultura de batata aumenta a intensidade da doença (29), devendo-se adotar a rotação de culturas com gramíneas, tais como arroz ou trigo, para reduzir a população de Streptomyces spp. $(15,19$, 28).

Solos neutros a levemente alcalinos são favoráveis a $S$. scabies, de modo que a calagem deve ser feita cuidadosamente, para não ultrapassar o pH 5,5 $(16,27)$. A severidade da doença é menor quando se empregam adubações nitrogenadas na forma de sulfato de amônio e uréia, visando reduzir o pH do solo (4, 17, 21). Em contraste, $S$. acidiscabies não é afetada em solos ácidos, tolerando $\mathrm{pH}$ de 3,8 in vitro (11).

A manutenção da umidade do solo elevada nos períodos de formação do tubérculo, assim como a redução das oscilações de umidade do solo contribuem para reduzir a severidade da doença (12).

A resistência de cultivares de batata à sarna comum tem sido considerada como de caráter quantitativo e parcial $(9,22,26)$, sendo poucas as cultivares disponíveis com elevada resistência. Entretanto, as cultivares de batata mais plantadas no Brasil não foram ainda devidamente avaliadas quanto à resistência a sarna comum nas condições edafoclimáticas do país.

Os objetivos deste trabalho foram: caracterizar isolados de Streptomyces spp., causadores da sarna comum profunda, quanto a critérios morfológicos e fisiológicos; avaliar o comportamento de seis cultivares de batata em relação à doença; e investigar a variação na agressividade entre os isolados de Streptomyces, em condições de vaso e ambiente aberto.

\section{MATERIAL E MÉTODOS}

Obtenção dos isolados de Streptomyces de tubérculos de batata Tubérculos de batata cultivar Monalisa (M) e Ágata (A) com sintomas de sarna comum profunda foram obtidos de campos de produção de batata de Casa Branca-SP (M1), Piedade-SP (M2), Bueno Brandão-MG (M3 e A1) e Ibicoara-BA (M4 e A2). Porções doentes dos tubérculos foram processadas a fim de se isolar o agente causal mediante técnica descrita por Ho \& Ko (6). Os isolados obtidos tiveram a patogenicidade confirmada em mini tubérculos da cv. Monalisa (13).

\section{Caracterização morfológica e fisiológica dos isolados de} Streptomyces

A análise morfológica foi realizada visualmente através do uso da microscopia óptica, avaliando-se o formato das cadeias de esporos e a coloração das colônias de Streptomyces, após 10 dias de crescimento em meio extrato de levedura e malte (YME) (3). A produção de melanina foi observada em meio de tirosina-ágar após 10 dias de crescimento e a habilidade em utilizar as fontes de carbono (L-arabinose, D-frutose, D-glicose, D-manitol, rafinose, raminose, sucrose e D-xilose) foi verificada em meio básico, constituído de: $2,64 \mathrm{~g}$ de $\left(\mathrm{NH}_{4}\right)_{2} \mathrm{SO}_{4}, 2,38$ $\mathrm{g}$ de $\mathrm{KH}_{2} \mathrm{PO}_{4}, 5,65 \mathrm{~g}$ de $\mathrm{K}_{2} \mathrm{H}_{2} \mathrm{PO}_{4} \cdot 3 \mathrm{H}_{2} \mathrm{O}, 1,0 \mathrm{~g}$ de $\mathrm{MgSO}_{4} .7 \mathrm{H}_{2} \mathrm{O}, 6,4$ $\mathrm{mg}$ de $\mathrm{CuSO}_{4} \cdot 5 \mathrm{H}_{2} \mathrm{O}, 1,1 \mathrm{mg}$ de $\mathrm{FeSO}_{4} \cdot 7 \mathrm{H}_{2} \mathrm{O}, 7,9 \mathrm{mg}$ de $\mathrm{MnCl}_{2} \cdot \mathrm{H}_{2} \mathrm{O}$, $1,5 \mathrm{~g} \mathrm{de} \mathrm{ZnSO}_{4} \cdot 7 \mathrm{H}_{2} \mathrm{O}, 15,0 \mathrm{~g}$ de ágar e $1000 \mathrm{~mL}$ de água destilada (10, 23). As fontes de carbono foram esterilizadas por filtração em membrana Millipore de $0,2 \mathrm{~mm}$ e adicionadas ao meio básico previamente autoclavado a $120^{\circ} \mathrm{C}$ por 20 minutos.

Comportamento das cultivares de batata a isolados de

\section{Streptomyces}

O experimento foi realizado no campo experimental do Setor de Fitopatologia, pertencente ao Departamento de Entomologia, Fitopatologia e Zoologia Agrícola da Escola Superior de Agricultura "Luiz de Queiroz", Universidade de São Paulo, Campus de Piracicaba, SP, com a primeira repetição instalada em abril de 2005 e a segunda em julho do mesmo ano.

O substrato autoclavado e composto de terra, esterco bovino e areia, na proporção de 2:1:1, apresentando $\mathrm{pH}$ em água de 6,3, foi infestado com uma suspensão de Streptomyces, incorporada nos primeiros $15 \mathrm{~cm}$ do solo, a razão de uma placa de Petri de $9 \mathrm{~cm}$ de diâmetro com meio de aveia, totalmente colonizada por 10 dias, por saco plástico com capacidade para $5 \mathrm{Kg}$ de solo $(3,4)$. A suspensão de Streptomyces foi preparada em liquidificador com $100 \mathrm{~mL}$ de água destilada por placa de Petri. Foram testados seis isolados (M1, M2, M3, M4, A1 e A2) e nas parcelas controle (sadias) incorporou-se ao solo $100 \mathrm{~mL}$ de água destilada por saco.

Batatas-sementes de seis cultivares amplamente cultivadas no Brasil (Ágata, Asterix, Cupido, Jaete Bintje, Monalisa e Mondial) sem sintomas de sarna comum foram plantadas sete dias após a infestação do solo, mantendo-se as plantas em ambiente aberto, seguindo um delineamento em blocos inteiramente ao acaso, com quatro repetições por tratamento, sendo cada parcela representada por um saco com uma planta.

As plantas receberam adubação de nitrogênio com nitrocálcio (5 g/planta) por ocasião da amontoa, 30 dias após o plantio, e procurouse manter a umidade do solo baixa, principalmente durante a tuberização, visando propiciar um ambiente mais favorável à bactéria $(3,12)$.

A avaliação da severidade da doença foi feita após a senescência natural de mais de $50 \%$ das plantas de cada cultivar, o que ocorreu entre 16-18 semanas após o plantio, estimando-se a porcentagem de área do tubérculo afetada de cada parcela com o auxílio da escala diagramática elaborada por James (8). Avaliou-se também o rendimento em peso de tubérculos de cada parcela. Os dados foram submetidos a análise de variância e para a comparação das médias foi empregado o teste de Tukey ao nível de $p<0,05$, sendo os dados de severidade previamente transformados para $\operatorname{arcsen}(\mathrm{x} / 100)^{1 / 2}$.

\section{RESULTADOS E DISCUSSÃO}

\section{Caracterização morfológica e fisiológica}

As colônias dos seis isolados de Streptomyces foram semelhantes quanto aos critérios morfológicos e fisiológicos avaliados. Apresentaram coloração cinza em meio de cultura YME. As cadeias de esporos se caracterizavam por serem espiraladas e produzidas sobre um micélio aéreo. Ocorreu produção de pigmento marrom escuro (melanina) em meio de tirosina-ágar, assim como a utilização das oito fontes de carbono empregadas para a caracterização das espécies de Streptomyces segundo recomendação da "International Streptomyces Project" (ISP) (23). Estas propriedades morfológicas e fisiológicas correspondem as descritas para S. scabies (10).

Comportamento de cultivares de batata a isolados de Streptomyces scabies

A severidade da sarna comum nas diferentes cultivares de batata, a agressividade dos isolados de $S$. scabies, assim como a produção de tubérculos ( $\mathrm{g} /$ planta) em função das cultivares e isolados variaram 
Tabela 1. Severidade $(\%)$ de sarna comum e redução na produção $(\%)$ em cultivares de batata

\begin{tabular}{|c|c|c|c|c|}
\hline \multirow[b]{2}{*}{ Cultivares } & \multicolumn{2}{|c|}{ Experimento 1} & \multicolumn{2}{|c|}{ Experimento 2} \\
\hline & Severidade $(\%)$ & $\begin{array}{l}\text { Produção }(\%) \\
\text { (sadia-doente) }\end{array}$ & Severidade $(\%)$ & $\begin{array}{l}\text { Produção }(\%) \\
\text { (sadia-doente) }\end{array}$ \\
\hline Mondial & $12,0 \mathrm{~A}^{1}$ & $-10,5$ & $9,0 \mathrm{~A}$ & $-12,8$ \\
\hline Jaete Bintje & $14,5 \mathrm{AB}$ & $29,3 *$ & $13,6 \mathrm{AB}$ & 23,3 \\
\hline Asterix & $17,4 \mathrm{~B}$ & 0,3 & $17,4 \mathrm{BC}$ & 5,6 \\
\hline Ágata & $23,6 \mathrm{C}$ & 0,5 & $20,0 \mathrm{C}$ & 15,5 \\
\hline Monalisa & $23,1 \mathrm{C}$ & 20,1 & $22,9 \mathrm{C}$ & 17,4 \\
\hline Cupido & $25,2 \mathrm{C}$ & 20,5 & $21,3 \mathrm{C}$ & 11,2 \\
\hline$\overline{\text { C.V. }(\%)}$ & 13,2 & & 25,7 & \\
\hline
\end{tabular}

${ }^{1}$ Dados seguidos pela mesma letra na coluna não diferem entre si (Tukey, $p<0,05$ ).

* Significativo a 0,05 .

Tabela 2. Severidade $(\%)$ de sarna comum e produção de tubérculos de batata (g/planta) em relação a isolados de Streptomyces scabies

\begin{tabular}{|c|c|c|c|c|}
\hline \multirow[t]{2}{*}{${\text { Isolados de } S \text {. } \text { scabies }^{1}}^{1}$} & \multicolumn{2}{|c|}{ Experimento 1} & \multicolumn{2}{|c|}{ Experimento 2} \\
\hline & Severidade & Produção (g) & Severidade & Produção $(\mathrm{g})$ \\
\hline$\overline{\text { Controle }}$ & $0,1 \mathrm{~A}^{2}$ & $232,4 \mathrm{AB}$ & $0,1 \mathrm{~A}$ & $219,2 \mathrm{AB}$ \\
\hline Monalisa-Casa Branca, SP (M1) & $5,7 \mathrm{~B}$ & $232,2 \mathrm{AB}$ & $6,6 \mathrm{~B}$ & $224,3 \mathrm{~A}$ \\
\hline Ágata- Ibicoara, BA (A2) & $15,1 \mathrm{C}$ & $260,6 \mathrm{~A}$ & $12,9 \mathrm{C}$ & $215,7 \mathrm{AB}$ \\
\hline Monalisa-Piedade, SP (M2) & $16,6 \mathrm{C}$ & $176,8 \mathrm{BCD}$ & $14,9 \mathrm{C}$ & 203,7 ABC \\
\hline Ágata-Bueno Brandão, MG (A1) & $17,8 \mathrm{C}$ & $141,1 \mathrm{D}$ & $16,8 \mathrm{C}$ & $189,6 \mathrm{ABC}$ \\
\hline Monalisa-Bueno Brandão, MG (M3) & $22,6 \mathrm{D}$ & $167,5 \mathrm{CD}$ & $20,9 \mathrm{C}$ & $184,0 \mathrm{BC}$ \\
\hline Monalisa-Ibicoara, BA (M4) & $37,4 \mathrm{E}$ & $217,8 \mathrm{ABC}$ & $31,9 \mathrm{D}$ & $169,2 \mathrm{C}$ \\
\hline$\overline{\text { C.V. }(\%)}$ & 14,3 & 33,5 & 27,6 & 21,0 \\
\hline
\end{tabular}

${ }_{2}^{1}$ Denominação de isolados de S. scabies: cultivar de batata-procedência (cidade, estado). As letras M e A referem-se as cvs. de batata Mosalisa e Ágata, respectivamente.

${ }^{2}$ Dados seguidos pela mesma letra na coluna não diferem entre si (Tukey, $p<0,05$ ).

significativamente $(p<0,05)$ (Tabelas 1 e 2). Entretanto, a severidade na interação cultivar e isolado não foi significativa (exp. 1, $p=0,1054$; exp. 2, $p=0,0793$ ), razão pela qual se optou por apresentar somente as médias dos isolados para cada variedade e vice-versa. Os valores de severidade e produção ( $\mathrm{g} /$ planta) foram similares entre os dois experimentos. Os isolados de S. scabies ocasionaram os mesmos tipos de sintomas de sarna profunda nas diferentes cultivares de batata.

As cvs. Mondial e Jaete Bintje foram as mais resistentes à sarna comum com severidade média nos dois experimentos de 10,5\% e 14,0\%, respectivamente, seguidas por Asterix (17,4\%), Ágata $(21,8 \%)$, Monalisa $(23,0 \%)$ e Cupido (23,3\%) (Tabela 1$)$. Com relação à produção de tubérculos, apenas Jaete Bintje apresentou significativa redução no primeiro experimento $(p<0,05)$, quando infectada por $S$. scabies comparada à sadia, sendo as cvs. Mondial, Asterix e Ágata as menos afetadas (Tabela 1).

$\mathrm{O}$ isolado de $S$. scabies M4 foi estatisticamente mais agressivo nos dois experimentos, com média de $34,7 \%$ de severidade, enquanto o isolado M1 com média de 6,2\% foi o menos agressivo. Para os demais isolados a severidade de sarna variou de 12,9 a 22,6\% (Tabela 2). Redução significativa da produção de tubérculos, em função da sarna, foi verificada para os isolados M2, A1 e M3 no primeiro experimento e para o isolado M4 no segundo experimento. A sarna comum é caracterizada por afetar a qualidade dos tubérculos, mas segundo Hiltunen et al. (7) infecções severas podem comprometer a produtividade da cultura.

A variabilidade nos níveis de resistência das cultivares a sarna comum e na agressividade dos isolados de S. scabies observados, assemelham-se aos descritos na literatura para outras cultivares e isolados da bactéria, em que a resistência é provavelmente quantitativa e infelizmente a maioria das cultivares são suscetíveis $(7,9,20)$. As diferenças na agressividade entre os isolados podem estar relacionadas à produção de taxtomina $\mathrm{A}$, uma fitotoxina envolvida no desenvolvimento dos sintomas de sarna comum (1). Garcia et al. (5) verificaram a produção de taxtomina A por estes isolados de $S$. scabies, entretanto, a quantificação da fitotoxina e sua correlação com a severidade dos sintomas de sarna comum seriam importantes para confirmar esta hipótese.

O nível de inóculo empregado neste trabalho pode ser considerado elevado quando comparado aos níveis que ocorrem naturalmente no campo. Incidência de tubérculos com sarna comum foi superior a $90 \%$, não havendo diferenças significativas $(p<0,05)$ entre as cultivares (dados não apresentados). Segundo Kobayashi et al. (9) a severidade apresentou crescimento linear com o aumento logarítmico $\left(\log _{10}\right)$ da densidade de inóculo. Entretanto, segundo o mesmo autor, as concentrações maiores de inóculo $\left(10^{5}-10^{7} \mathrm{ufc} / \mathrm{g}\right.$ solo) permitiram a obtenção de resultados mais consistentes, sem a ocorrência de escapes, em relação à resistência de cultivares de batata. A avaliação preliminar de cultivares de batata para resistência a sarna comum em menor escala (vasos), sob condições controladas de inóculo do patógeno, tipo de solo e umidade, caracteriza-se um passo importante para estudos subseqüentes em condições de campo, onde a resposta à sarna é freqüentemente variável em função das variações climáticas anuais durante o período crítico de desenvolvimento da doença e variações na infestação do solo, razão 
pela qual são necessários ensaios de vários anos para se obter resultados confiáveis (20).

A classificação de cultivares quanto à resistência à sarna comum pode ser uma importante ferramenta no controle integrado da doença. A caracterização dos isolados de Streptomyces nacionais seria de extrema importância, pois a suscetibilidade das cultivares pode variar com a espécie/raça da bactéria (20).

\section{AGRADECIMENTOS}

Os autores agradecem ao Prof. Dr. Hiroshi Kimati (in memoriam) pelos valiosos conselhos no planejamento e execução do trabalho.

\section{REFERÊNCIAS BIBLIOGRÁFICAS}

1. Bukhalid, R.A.; Loria, R. Cloning and expression of a genes from Streptomyces scabies encoding a putative pathogenicity factor. Journal of Bacteriology, Washington, v.179, p.7776-83, 1997

2. Faucher, E.; Paradis, E.; Goyer, C.; Hodge, N.C.; Hogue, R.; Stall, R.E.; Beaulieu, C. Characterization of Streptomyces causing deeppitted scab of potato in Québec, Canada. International Journal of Systematic Bacteriology, New York, v.45, n.2, p.222$225,1995$.

3. Fischer, I.H.; Kimati, H.; Martins, M.C. Isolamento, caracterização cultural-morfológica, patogenicidade e serologia de Streptomyces spp. da batata. Fitopatologia Brasileira, Fortaleza, v. 28, n.6, p.650-655, 2003.

4. Fischer, I.H.; Martins, M.C.; Lourenço, S.A.; Kimati, H. Efeito de fertilizantes e fungicidas na incidência da sarna da batata. Summa Fitopatológica, Botucatu, v.31, n.3, p.263-266, 2005.

5. Garcia, E. O.; Fischer, I.H.; Macagnan, D.; Pascholati, S.F.; Almeida, I.M.G.; Beriam, L.O.S. Resistência de cultivares de batata a isolados de Streptomyces spp., com diferentes níveis de produção de taxtomina A. Summa Phytopathologica, Botucatu, v.33, p.56. 2007. (Resumo 185).

6. Ho, W.C.; Ko, W.H. Alkalized water agar as a selective medium for enumerating soil actinomycetes. Phytopathology, California, v.69, n.9, p.1031, 1979. (Abstract).

7. Hiltunen, L.H.; Weckman, A.; Ylhäinen, A.; Rita, H.; Richter, E.; Valkonen, J.P.T. Responses of potato cultivars to the common scab pathogens, Streptomyces scabies and S. turgidiscabies. Annals of Applied Biology, Warwick, v.146, p.395-403, 2005.

8. James, W.C. An illustrated series of assessment keys for plant diseases, their preparation and usage. Canadian Plant Disease Survey, Ottawa, v.51, n.2, p.39-65, 1971.

9. Kobayashi, A.; Nalto, S.; Kobayashi, Y.O.; Tsuda, S.; Ohara-Takada, A.; Mori, M. Precise, simple screening for resistance in potato varieties to common scab using paper pots. Journal of General Plant Pathology, Hokkaido, v.71, n.2, p.139-143, 2005.

10. Lambert, D.H.; Loria, R. Streptomyces scabies sp. nov., nom. rev. International Journal of Systematic Bacteriology, New York, v.39, n.4, p.387-392, 1989a.

11. Lambert, D.H.; Loria, R. Streptomyces acidiscabies sp. nov., nom. International Journal of Systematic Bacteriology, New York, v.39, n.4, p.393-396. 1989b.

12. Lewis, B.G. Effects of water potencial on infection of tubers by Streptomyces in soil. Annals of Applied Biology, Warwick, v.66, p.83-88, 1970.
13. Lindholm, P.; Kortema, H.; Kokkola, M.; Haahtela, K.; Sakinoja-Salonem, M.; Valkonen, J.P.T. Streptomyces spp. isolated from potato scab lesions under Nordic conditions in Finland. Plant Disease, Saint Paul, v.81, n.11, p.1317-1322, 1997.

14. Loria, R.; Kers, J.; Joshi, M. Evolution of plant pathogenicity in Streptomyces. Annual Review of Phytopathology, Palo Alto, v.44, p.469-87, 2006.

15. Matsuzaki, M.; Hamaguchi, H.; Shimonasako, H. The effect of manure application and soil fumigation on the field crops cultivated continuously. Research Bulletin of the Hokkaido National Agricultural Experiment Station, Hokkaido, n.66, p.1$65,1998$.

16. Mishra, B.B.; Srivastav, J.S. Effect of pH on the common scab disease of potato. Environment and Ecology, Varanasi, v.14, n.2, p.387-389, 1996.

17. Mizuno, N.; Yoshida, H.; Ushiki, J.; Tadano, T. Effect of fertilization method on the suppression of potato common scab in allophanic Andosols. Japanese Journal of Soil Science and Plant Nutrition, Tokyo, v.68, n.6, p.686-689, 1997.

18. Miyajima, K.; Tanaka, F.; Takeuchi, T.; Kuninaga, S. Streptomyces turgidiscabies sp. nov. International Journal of Systematic Bacteriology, New York, v.48, n.2, p.495-502, 1998.

19. Park, Y.; Yiem, M.; Cho, J.; Park, Y.B., Yiem, M.S.; Cho, J.L. Development of integrated control system on potato common scab (Streptomyces scabies) of 'Dejima' potatoes. Journal of the Korean Society for Horticultural Science, Suwon, v.43, n.6, p.710-715, 2002.

20. Pasco, C.; Jouan, B.; Andrivon, D. Resistance of potato genotypes to common and netted scab-causing species of Streptomyces. Plant Pathology, Oxford, v.54, p.383-392, 2005.

21. Pavlista, A.D. Early-season applications of sulfur fertilizers increase potato yield and reduce tuber defects. Agronomy Journal, Madison, v.97, p.599-603, 2005.

22. Pfeffer, C.; Effmer, M. Die Zuchtung homozygoter durch Streptomyces scabies (Thaxt.) Waksman and Henrici. Arch Züchtungsforsch, Berlin, v.15, p.325-333, 1985.

23. Shirling, E.B.; Gottlieb, D. Methods for characterization of Streptomyces species. International Journal of Systematic Bacteriology, New York, v.16, p.313-340, 1966.

24. Takeuchi, T.; Sawada, H.; Tanaka, F.; Madsuda, I. Phylogenetic analysis of Streptomyces spp. causing potato scab based on $16 \mathrm{~S}$ rRNA sequences. International Journal of Systematic Bacteriology, New York, v.46, n.2, p.476-479, 1996.

25. Toth, L.; Maeda, M.; Tanaka, F.; Kobayashi, K. Isolation and identification of pathogenic strains of Streptomyces acidiscabies from netted scab lesions of potato tubers in Hokkaido (Japan). Acta Microbiologica et Immunologica Hungarica, Budapest, v.48, p.575-585, 2001.

26. Wastie, R.T. Inheritance of resistance to fungal diseases of tubers. In: Bradshaw, J.E.; Mackay G.R. Potato genetics. CAB International, Wallingford, 1994. p 419-421.

27. Waterer, D. Impact of high soil $\mathrm{pH}$ on potato yields and grade losses to common scab. Canadian Journal of Plant Science, Saskatoon, v.82, n.3, p.583-586, 2002.

28. Wiggins, B.E.; Kinkel, L.L Green manures and crop sequences influence potato diseases and pathogen inhibitory activity of indigenous streptomycetes. Phytopathology, California, v.95, p. 178-185, 2005

29. Zarina, L.; Metspalu, L.; Mitt, S. Resistance of potato to pests and diseases in different crop rotations. Transactions of the Estonian Agricultural University, Priekuli, n.209, p.243-245, 2000. 